University of Wollongong

Research Online

Faculty of Social Sciences - Papers (Archive) Faculty of Arts, Social Sciences \& Humanities

2015

Recognising aspiration: The AIME program's effectiveness in inspiring Indigenous young people's participation in schooling and opportunities for further education and employment

Valerie Harwood

University of Wollongong, vharwood@uow.edu.au

Samantha McMahon

University of Wollongong, smcmahon@uow.edu.au

Sarah Elizabeth O'Shea

University of Wollongong, sarah.oshea@curtin.edu.au

Gawaian Bodkin Andrews

University of Technology, Sydney

Amy Priestly

Australian Indigenous Mentoring Experience (AIME)

Follow this and additional works at: https://ro.uow.edu.au/sspapers

Part of the Education Commons, and the Social and Behavioral Sciences Commons

Research Online is the open access institutional repository for the University of Wollongong. For further information contact the UOW Library: research-pubs@uow.edu.au 


\title{
Recognising aspiration: The AIME program's effectiveness in inspiring Indigenous young people's participation in schooling and opportunities for further education and employment
}

\author{
Abstract \\ A strong feature of the widening participation agenda is improving the aspirations of groups that are \\ underrepresented in higher education. This paper seeks to reposition the utility of this as a focal point of \\ educational interventions by showcasing the success of a mentoring program that takes a different \\ approach. The Australian Indigenous Mentoring Experience (AIME) significantly and positively impacts \\ Australian Indigenous high school students' aspirations to finish school and continue to further study, \\ training or employment. AIME is not read as a classic intervention program for raising aspirations. \\ Instead, AIME builds upon the cultural wealth of participants and adopts an approach that seeks to \\ inspire individuals rather than remediate them. The paper draws on survey data and fieldwork to present \\ an example case study for resisting the assumption that young people's aspirations are deficit and in \\ need of 'improving'. The paper describes how AIME works within young people's 'windows of aspiration' to \\ positively impact their engagement in school and further education, training and employment.

\section{Keywords} \\ participation, people, young, education, inspiring, effectiveness, program, aime, aspiration, recognising, \\ further, opportunities, indigenous, schooling, employment \\ Disciplines \\ Education | Social and Behavioral Sciences

\section{Publication Details} \\ Harwood, V., McMahon, S., O'Shea, S., Bodkin-Andrews, G. \& Priestly, A. (2015). Recognising aspiration: \\ The AIME program's effectiveness in inspiring Indigenous young people's participation in schooling and \\ opportunities for further education and employment. The Australian Educational Researcher, 42 (2), \\ 217-236.
}




\title{
Recognising Aspiration: \\ The AIME program's effectiveness in inspiring Indigenous young people's participation in schooling and opportunities for further education and employment
}

\author{
Valerie Harwood, UOW \\ Samantha McMahon, UOW \\ Sarah O'Shea, UOW \\ Gawaian Bodkin-Andrews, UTS \\ Amy Priestly, AIME Mentoring
}

\begin{abstract}
A strong feature of the widening participation agenda is improving the aspirations of groups that are underrepresented in higher education. This paper seeks to reposition the utility of this as a focal point of educational interventions by showcasing the success of a mentoring program that takes a different approach. The Australian Indigenous Mentoring Experience (AIME) significantly and positively impacts Australian Indigenous high school students' aspirations to finish school and continue to further study, training or employment. AIME is not read as a classic intervention program for raising aspirations. Instead, AIME builds upon the cultural wealth of participants and adopts an approach that seeks to inspire individuals rather than remediate them. The paper draws on survey data and fieldwork to present an example case study for resisting the assumption that young people's aspirations are deficit and in need of 'improving'. The paper describes how AIME works within young people's 'windows of aspiration' to positively impact their engagement in school and further education, training and employment.
\end{abstract}




\section{Introduction}

Obstacles are there to get around, climb over or scramble through (Pat O'Shane, Kunjandii Woman, Retired Magistrate).

We're all gifted with the opportunity to succeed. But you get further if you extend the hand of friendship.

(Jimmy Little, Yorta Yorta Man, AO, Songwriter and Musician)

We believe that Indigenous $=$ Success and expect all kids in our Program to succeed (aimementoring.com).

The idea of raising aspirations is now a well-used motif in much of the current efforts to redress the varying educational outcomes of young people across different socio-cultural groups. The idea has been variously critiqued, not least because it can imply the assumption that not succeeding in education indicates a lack of aspirations. Not surprisingly, there are recognised problems with current usage of aspiration when applied to low socio-economic status young people (LSES) (Kenway and Hickey-Moody 2011; Sellar et al. 2011). Concern has been raised over the emphasis on neoliberal discourses (Raco 2009) where structural factors are elided and hopes and aspirations of LSES children and families are misinterpreted. For example, the rhetoric of aspiration discourses can result in young people being framed in deficit ways; with low aspirations tied to 'lack of effort', 'laziness', and to 'uncaring' parents, caregivers and families. Such misinterpretations have the dangerous potential to racialise young Indigenous Australians, and in so doing, perpetuate erroneous racist and colonising beliefs and assumptions.

Appadurai's (2004) theory of the capacity to aspire and concept of 'narrow aspiration windows' is useful counter to neo-liberal discourses that might deficitise Indigenous young people. By re-orientating the emphasis onto what is available/ unavailable to those experiencing poverty, the metaphor of 'narrow aspiration windows' makes explicit what is unavailable to people, as opposed to what is lacking within them. Thus in Appadurai's view, aspiration is connected to having the requisite aspiration window. Consequently, the notion of low aspiration is better understood as a navigational capacity where the capacity to aspire is underpinned by the resources to which an individual has access. Yet we suggest, while the focus on navigation helps to highlight how the capacity to aspire might manifest, this is not, on its own, sufficient. This paper seeks to both trouble and think through the ideas of aspiration by engaging with ideas from Appadurai (2004) and Yosso (2005).

We depart from a stance of 'low aspiration' and consider an approach that we maintain is premised on the idea of recognising aspiration. Drawing on Yosso's (2005) Community Cultural Wealth framework, with particular reference to aspirational capital, the paper focuses on how aspiration is done differently in the Australian Indigenous Mentoring Experience (AIME). AIME connects Indigenous high school students with university students, running programs in five Australian states (NSW, VIC, SA, WA, QLD) and the Australian Capital Territory. Significantly, the program operates from the explicit assumption that 'Indigenous $=$ Success' (aimementoring.com), a stance that 
arguably differs from much of the deficit focused educational programs that invoke the idea of aspiration. Drawing from our extensive research with AIME over a 4 year period, we put forward the argument that recognition of aspiration is foundational in this program. In this sense, AIME innovatively inspires Indigenous young people's participation in education.

In the next section we outline the background to Yosso's framework and then provide an overview of the AIME program. Following this we describe the research design and the qualitative and quantitative methods used in our research with AIME. This leads to our analysis of the AIME program. To begin, we provide a brief outline of our previous quantitative survey of AIME mentees to show that the program does influence the mentees' aspirations. We then turn to the qualitative data to discuss three key ways that the AIME mentoring program works to recognise the aspirations of the Indigenous young people. These are: (1) providing educational settings and relationships characterised by high expectations; (2) inspiring mentee understandings of what it means to be Indigenous; and (3) navigating existing aspiration windows with existing aspiration capitals - meeting the mentees where they are at.

\section{Cultural capital,aspiration and the AIME program}

Bourdieu $(1977,1986,1997)$ has been credited with recognising the deeply political nature of culture and cultural knowledge, identifying how certain forms and practices are more valued than others; a form of systemic inequity played out across institutions including education. As Dumais and Ward (2009) argue:

In the educational system, while on the surface it appears that students are being rewarded because of their natural academic talents, in fact they are being rewarded for their cultural capital (p. 247).

Bourdieu (1986) defines cultural capital in terms of three states (1) objectified in tangible goods, (2) institutionalised as academic credentials and (3) embodied by "dispositions of the mind and body" (p. 243) or habitus. The term has also entered public discourse as a means to signify advantage or disadvantage as it is assumed those in higher status groups will have greater access to valued capitals compared to those who are identified as being in the lower strata of society (Dumais and Ward 2009). For example, McDonough (1997) argues that certain forms of cultural capital impact positively on college selection, with those from higher status or more privileged backgrounds having deeper knowledge and understanding about college selection processes.

Whilst useful for identifying the extent and effects of dominant cultural capital, Yosso (2005) draws attention to the problem of assuming a "lack" of cultural capital, positioning those without as "culturally poor" (p. 76). This can effectively negate these individuals as lacking. Yosso and Garcia (2007) argue that Bourdieu's theories have been hi-jacked and "interpreted through a deficit lens" (p. 153), which overlooks the cultural capitals of non-dominant groups and peoples. In this paper we draw on Yosso's (2005) Community Cultural Wealth framework. This framework is a strengths based model that recognises the mulitple capitals that reside within 
communities and individuals. Of particular interest in this study was aspirational capital which Yosso (2005) defines as referring to an individual's ability to maintain hope and dreams for the future despite real and perceived obstacles. This is a form of resilience which enables individuals to "dream of possibilities beyond their present circumstances, often without the objective means to attain those goals" (p. 78). This interpretation recognises a significant positive force in the young people. Taking cues from Yosso's (2005) argument that "Communities of Color are places with multiple strengths" (p. 82) we also argue that the young people who come to AIME come from Indigenous Communities with multiple strengths. Furthermore, we maintain, this includes high expectations.

The trouble, as we see it, and as Yosso (2005) so cogently persuades us, is the way that the cultural capital of the White middle classes is held as the norm. There is thus a desperate need to de-center education's views of young Indigenous people away from the hegemony of a dominant cultural capital. Such views too often cast these young people as lacking high expectations. On the contrary, and to some it might be provocatively, we take the position that the Indigenous young people have high expectations, and, as we will later make the case, these can be present at the same time as not expecting (or thinking about) going to university. The idea here is to refocus the way cultural capital grips and dominates readings of education and, instead look for the cultural wealth that exists. By taking this approach it becomes possible to see something quite different. In Yosso's words, the "multiple forms of cultural wealth within Communities of Colour... aspirational, social, navigational, linguistic, resistant and familial capital” (2005, p. 82).

Starting from this perspective, we argue that AIME supports this strengths based model, facilitating a culture of possibility through both its curriculum and ethos. Participants in AIME are encouraged to not only dream or imagine these possibilities but also be better prepared to draw upon existing capitals and knowledges in order to enact these dreams.

\section{The AIME program}

The AIME program is designed to support Indigenous Australian high school students through high school and into university, further education or employment at the same rate as every Australian child. All Indigenous students in years 7-12, from schools participating in AIME, are invited to attend (please see AIME annual reports for more detail, accessible from aimementoring.com). The AIME mentoring program has a well-established curriculum in the form of workbooks, interactive multimedia and session plans used, respectively, by the mentees/mentors and the AIME presenters. AIME seeks to ensure that presenters are young Indigenous Australian role models, who are supported by an AIME team that includes both Indigenous and non-Indigenous staff. The AIME curriculum has been designed by and for Indigenous people and has received ongoing evaluation via mentee, mentor, teacher and AIME staff feedback. This has resulted in a set of materials that have been refined over AIME's 10 years of operation, which are distributed to all AIME sites across Australia. There are different programs designed for each scholastic year

group. 
The program curriculum is delivered at university campuses across Australia (current programs in 18 universities across QLD, NSW, ACT, VIC, SA and WA). The AIME presenters deliver the AIME curriculum to groups of Indigenous highschool students and their university student mentors. During program delivery, the mentors sit with the mentees and encourage and support them through tasks; they also act as accessible role models who have succeeded in completing their high school education and continued their education in tertiary settings. The mentors are volunteer university students who are are completing different degrees at various levels of study.

There are two modes of delivering the AIME program: university based structured programs and school based tutor squads. The most common mode is the university based programs, where high school students attend a University campus on excursion from school (they arrive in taxis, buses or via public transport with a teacher or education officer). This mode offers delivery of the AIME curriculum to schools located within a 2-hour commute from the university campus. It is the year 9-12 programs in this university-based mode of delivery that are the focus of this study. The second mode of delivery is Tutor Squads, where AIME deploys groups of university student mentors into the schools for additional one on one tutoring to support mentees' homework completion throughout the year.

Since its inception the program has experienced exponential growth and great success for its mentees. Starting out with only 25 mentors and 25 mentees at one university site in 2005, in 2013 the program comprised 1066 university student mentors and 2789 mentees at 23 university campuses across Australia (AIME 2014). To date AIME has been shown to be effective in improving school retention and further education rates (AIME 2014; Bodkin-Andrews et al. 2013; Harwood et al. 2013). The positive impact on mentees has been established by large-scale evaluation research in 2012 (Harwood et al. 2013) and the positive economic impact of the program for mentees and the Australian economy has been established (KPMG 2013). This paper hopes to demonstrate how AIME engages and recognises mentees' aspirations. There is no assumption that these young people fail to aspire or have any kind of aspiration deficit. Instead, we argue that AIME is premised upon the understanding that all participants are replete with aspirational capital, that their existing values, beliefs, understandings and practices are strengths. The analysis section will demonstrate that the AIME curriculum, presenters and mentors collaborate, in sometimes precariously narrow aspiration windows, to acknowledge, confirm and strengthen the existing aspirations of these young people.

\section{Research design}

The AIME Partnership Project is a research partnership between AIME and researchers at two Australian universities (Faculty of Social Sciences, University of Wollongong and the University of Technology, Sydney). The project follows the AIATSIS research protocols (2011) and has the appropriate human research ethics approval. The research design incorporates a mixed-method approach, drawing on in-depth qualitative fieldwork together with quantitative surveys. This paper draws 
Table 1 Geographic distribution of research sites (university campuses) for ethnographic observations

\begin{tabular}{|c|c|c|c|c|c|}
\hline & \multicolumn{2}{|c|}{ Sites for multiple observation days } & \multicolumn{2}{|c|}{ Sites for singular observation days } & \multirow[t]{2}{*}{ Totals } \\
\hline & Metropolitan & Regional & Metropolitan & Regional & \\
\hline QLD & - & 1 & - & - & 1 \\
\hline NSW & 1 & 3 & - & - & 4 \\
\hline ACT & 1 & - & - & - & 1 \\
\hline VIC & - & 1 & 2 & - & 3 \\
\hline SA & 1 & - & - & - & 1 \\
\hline WA & 1 & - & 4 & - & 5 \\
\hline Totals & 4 & 5 & 6 & 0 & 15 \\
\hline
\end{tabular}

on qualitative fieldwork conducted in 2014 and on our survey analysis from 2012 (2014 survey data is not yet available). ${ }^{1}$

\section{Qualitative fieldwork}

A team of researchers conducted ethnographic observations of 150 AIME sessions during 56 AIME program days, at 15 university campuses across Australia. Nine of the 15 campuses were targeted for repeat visits from a single researcher to develop continuity and depth in the observational data. The remaining six sites were observed for only one program day. The effect of this site selection was that the researchers were able to observe the same AIME curriculum delivered across multiple research sites and contexts. A summary of the geographic distribution of the research sites (university campuses) is included in Table 1.

During observation days the researchers also conducted semi-structured interviews with AIME mentees $(\mathrm{N}=86)$ and mentors $(\mathrm{N}=79)$ to capture their experiences of and responses to AIME. A summary of the interview data collected to date is available at Table 2 .

\section{Quantitative survey}

Whilst statistical frameworks have been long, and in many cases rightfully, treated with a distinct level of mistrust from Indigenous community and researcher perspectives, a number of national and international Indigenous scholars have been able to place analytical strategies firmly within Indigenous Research Methodological Frameworks (Walter and Andersen 2013). Drawing from such research, our project has committed to a proactive and culturally sensitive statistical research lens. Consequently, the positive experiences of the mentees within AIME, and their relations with desirable educational and life outcomes were examined. Drawing from earlier data collected in 2012 for an evaluation of the AIME program

\footnotetext{
1 Data collection for this mixed-methods project completion in 2015. Exact numbers of survey participant are yet to be advised. At the time of writing we had interviewed a total of 125 mentees and 77 mentors).
} 
Table 2 Summary of interview data to date

\begin{tabular}{lcccccr}
\hline & Year 9 & Year 10 & Year 11 & Year 12 & University & Totals \\
\hline Mentees & & & & & & \\
Male & 5 & 22 & 5 & - & - & 32 \\
Female & 13 & 20 & 17 & 4 & - & 54 \\
Mentors & & - & - & - & 24 & 24 \\
Male & - & - & - & - & 55 & 55 \\
Female & - & 42 & 22 & 4 & 79 & 165 \\
Totals & 18 & & & & & \\
\hline
\end{tabular}

(Harwood et al. 2013), a small sample of mentees completed surveys (created in consultation with the AIME Research Director) capturing previously utilised positive measures in pre-existing Aboriginal education research (e.g., BodkinAndrews et al. 2010a, b), and questions specifically tailored from earlier qualitative findings emerging from the voices of AIME mentors and mentees.

Six hundred and ten (610) surveys were posted to mentee participants and 91 surveys were returned (whilst the $14.91 \%$ response rate is low, this may be explained by the administration during December holidays and the need for responses from both mentees and their parents).

Table 3 Variables used for survey analysis

\begin{tabular}{|c|c|}
\hline Variable & Description \\
\hline AIME Experience & $\begin{array}{l}\text { A single item question capturing mentees' overall } \\
\text { experiences of AIME-“Overall what has your } \\
\text { experience with AIME been like?" Responses ranged } \\
\text { from Very Bad (1) to Very Good (7) }\end{array}$ \\
\hline $\begin{array}{l}\text { Academic self-concept and general self- } \\
\text { esteem scales Marsh et al. (2005) }\end{array}$ & $\begin{array}{l}\text { Two factors drawn from the larger Self-Description } \\
\text { Questionnaire II- Short Version) that captured students' } \\
\text { over positive feelings about themselves (I have a lot to } \\
\text { be proud of) and school (I am good at most school } \\
\text { subjects). Answers ranged from False (1) to True (6) }\end{array}$ \\
\hline $\begin{array}{l}\text { Aboriginal pride Dobia et al. (2014) and } \\
\text { cultural safety scale Craven et al. (2013) }\end{array}$ & $\begin{array}{l}\text { Two factors assessing the extent to which Aboriginal } \\
\text { students are proud of their culture (e.g., Being } \\
\text { Aboriginal gives me strength) and feel confident about } \\
\text { their culture within the school (e.g., I feel comfortable } \\
\text { with being Aboriginal in school). Answers ranged from } \\
\text { False (1) to True (6) }\end{array}$ \\
\hline School and post school aspirations & $\begin{array}{l}\text { Two single item questions capturing when students } \\
\text { would like to leave school, and what they would like to } \\
\text { do after school }\end{array}$ \\
\hline Demographic variables & $\begin{array}{l}\text { A series of question capturing student background } \\
\text { variables including gender, grade, School Socio- } \\
\text { economic Status (drawn from www.myschool.edu.au), } \\
\text { Home educational resources (e.g., computer, desk to } \\
\text { study on), and parental educational attainment at } \\
\text { university }\end{array}$ \\
\hline
\end{tabular}


The statistical techniques utilised consisted of simple mean and frequency analyses for the key variables (utilising IBM SPSS) and a nested regression modelling approach (Harlow 2014) to ascertain if "AIME experience" can significantly account for variance in academic aspirations, general self-esteem, school selfconcept, Aboriginal pride and cultural safety after accounting for the demographic variables (Table 3).

\section{Mentee aspirations and mean scores}

Figure 1 provides frequency scores for the AIME mentees' aspiration to complete year 12, and Fig. 2 depicts their post school aspirations. It can be noted that the majority of AIME mentees aspire to complete year 12 (81 at $89.0 \%$ ) and to go to university (40 at $44.0 \%$ ). When collapsing the results for Fig. 2 into clearly defined study/working aspirations versus haven't decided or other (e.g., holiday), one can note that $68(74.3 \%)$ of AIME mentees have clear post school aspirations.

With regards to the mean scores for the 'AIME experience', the positive selfperception and culture variables, the results from Table 4 suggest that the mentee responses were all exceptionally positive.

Overall the results suggest that AIME may be promoting a stronger sense of: aspirations to complete year 12 and to have definitive post school aspirations, stronger self-perceptions, and culture within the AIME mentees. The nature of these analyses make it difficult to come to such a conclusion (e.g., no control sample, or longitudinal data). However, when comparing these results to other studies involving Indigenous students, it can be noted that the mean scores do seem higher for the self-perception variables (see Bodkin-Andrews et al. 2010a, b) and culture variables (see Craven et al. 2013). The suggestion that there is a stronger sense of varying aspirations does not assume that aspirations were necessarily lacking prior to AIME, a point to which we return in the following sections.

\section{AIME experiences, self-perceptions and culture}

To further examine the possible validity of this conclusion, Table 5 provides the results for regression analyses that sought to determine where positive AIME experiences predict positive aspirations, self-perceptions, and pride in culture after controlling for the student background variables.

Fig. 1 When would you like to leave school?

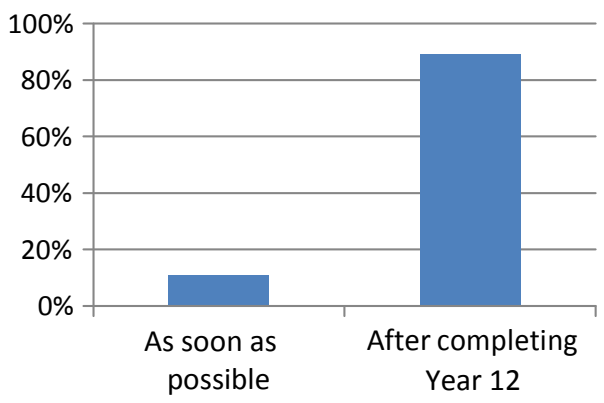


Fig. 2 What would you like to do after you leave school?
Table 4 Mean responses for AIME experiences, selfperception, and culture variables

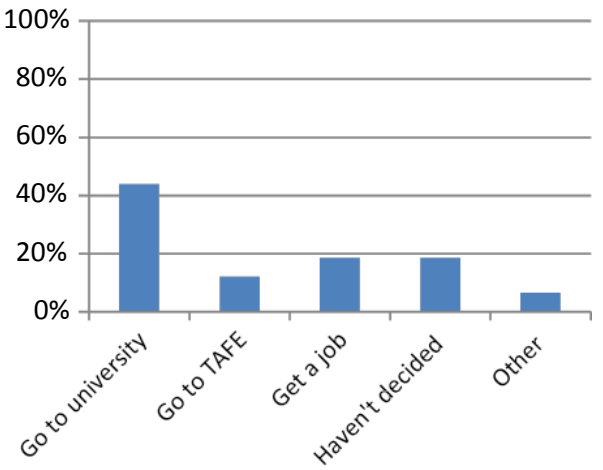

\begin{tabular}{llrr}
\hline & Response range (item range) & Mean & SD \\
\hline AIME experience & $4-7(1-7)$ & 6.58 & .65 \\
Self-esteem & $3-6(1-6)$ & 5.14 & .75 \\
School self-concept & $1-6(1-6)$ & 4.18 & 1.15 \\
Aboriginal pride & $3-6(1-6)$ & 5.48 & .69 \\
Cultural safety & $2-6(1-6)$ & 5.46 & .86 \\
\hline
\end{tabular}

Within Table 5 it can be noted that for the most part, the predictive paths emanating from demographic background variables (ran in Model 1) were not associated with the outcome variables. With that being said, for school aspirations $13.1 \%$ of the variance was explained (with increased home educational resources approaching significance); for post-school aspirations $18.3 \%$ of the variance was explained (with later year groups significantly predicting higher aspirations); for self-esteem $4.5 \%$ of the variance was explained (no significant predictors), for school self-concept $11.8 \%$ of the variance was explained (with later year groups significantly predicting a stronger school self-concept), for Aboriginal pride $23.7 \%$ of the variance was explained (with a later year groups and parents completing university significantly predicting higher Aboriginal pride), and for cultural safety $7.8 \%$ of the variance was explained (no significant predictors). With the inclusion of the AIME experience measure within Model 2, it can be noted that positive AIME experiences significantly (or approaching) and positively contributed to school aspirations (16.4\% of variance explained), self-esteem $(17.6 \%$ of variance explained), school self-concept (14.4\% of variance explained).

Overall, the quantitative results offer an insight into the potential influence impact of the AIME experiences upon the mentee school and post-school aspirations and self-perce tions, particularly surrounding the desire to finish school, and their positive feelings their sense of self (self-esteem), and their confidence at school (school self-concept). Whilst the results may seem somewhat muted for university aspirations and the cultural variables, it is critical that readers understand the diversity of positive experiences offered by specific AIME activities 
Table 5 Predictive modelling for aspirational, self-perceptions, and culture outcomes

\begin{tabular}{|c|c|c|c|c|c|c|c|c|c|c|c|c|}
\hline & \multicolumn{2}{|l|}{$\begin{array}{l}\text { School } \\
\text { aspire }\end{array}$} & \multicolumn{2}{|c|}{$\begin{array}{l}\text { Post-school } \\
\text { aspire }\end{array}$} & \multicolumn{2}{|c|}{ Self-esteem } & \multicolumn{2}{|c|}{$\begin{array}{l}\text { School self- } \\
\text { concept }\end{array}$} & \multicolumn{2}{|c|}{$\begin{array}{l}\text { Aboriginal } \\
\text { pride }\end{array}$} & \multicolumn{2}{|c|}{$\begin{array}{l}\text { Cultural } \\
\text { safety }\end{array}$} \\
\hline & b & Sig & $\mathrm{b}$ & Sig & $\mathrm{b}$ & Sig & $\mathrm{b}$ & Sig & $\mathrm{b}$ & Sig & $\mathrm{b}$ & Sig \\
\hline \multicolumn{13}{|l|}{ Model 1} \\
\hline $\begin{array}{l}\text { Outreach/ } \\
\text { Core }\end{array}$ & .15 & ns & .08 & ns & -.01 & ns & .12 & ns & -.09 & ns & -.18 & ns \\
\hline Gender & .14 & ns & -.05 & ns & -.05 & $\mathrm{~ns}$ & -.05 & ns & -.01 & ns & -.00 & ns \\
\hline Year & .18 & ns & $.37 *$ & .001 & .13 & ns & $.22 *$ & .03 & $.29 *$ & .005 & .16 & ns \\
\hline School SES & .08 & ns & -.12 & ns & -.04 & ns & -.10 & ns & .09 & ns & -.03 & ns \\
\hline $\begin{array}{l}\text { Home } \\
\text { educational } \\
\text { resources }\end{array}$ & $.17^{\wedge}$ & .09 & .01 & ns & .13 & ns & .15 & ns & -.14 & ns & -.14 & $\mathrm{~ns}$ \\
\hline $\begin{array}{l}\text { Parental } \\
\text { university }\end{array}$ & -.10 & ns & -.12 & ns & -.02 & $\mathrm{~ns}$ & -.10 & ns & $.39 *$ & .001 & .16 & $\mathrm{~ns}$ \\
\hline \multicolumn{13}{|l|}{ Model 2} \\
\hline $\begin{array}{l}\text { AIME } \\
\text { experience }\end{array}$ & .19 & .05 & .04 & ns & .37 & .001 & $.16^{\wedge}$ & .09 & .08 & ns & .12 & ns \\
\hline
\end{tabular}

b Standardised predictive path, Sig significance, Outreach/Core AIME mentee who participated in the Outreach program (1) or the Core program (2) Post-school Aspire Study (e.g., Uni) or working aspirations (1) or other (e.g., holiday) or no idea (2)

$* \mathrm{p} \backslash 05, \wedge \mathrm{p} \searrow 10$

(e.g., leadership, study skills, pathways to university, cultural teachings). Therefore from a quantitative perspec- tive, future analyses should examine questions relating to these specific experiences as opposed to an overall general experience measure. Alternatively, particularly around cultural measures, the voices of the students themselves may best capture the cultural strength found in schooling and the AIME experiences (Munns et al. 2013). The voices of the mentees interviewed in our qualitative work provides further insight into individual experiences of AIME and how this involvement affected their education.

\section{Recognising and engaging with aspirations through high expectations and quality support}

AIME conceptualise and promote their program as meeting a deficit of the educational system, as opposed to a deficit of the young person. Rather than focusing on raising the individual mentee's aspirations, the program focuses on ameliorating the low expectations and lack of support that Indigenous young people encounter in school settings (Sarra 2011). For example, this shift was encapsulated by an AIME staff member during one mentor briefing provided at the beginning of 
an AIME program day. This presenter explained that AIME works by "setting high expectations and providing quality support" (Fieldnotes May 2014, ACT) and ensuring mentees are held accountable for their participation in education. This focus on aspirations manifests at both a macro and micro level.

On a macro level, AIME focuses responsibility for educational aspirations by embedding a contract into the curriculum between the mentees and the AIME program, staff and volunteers. In the first session of the program, mentees are asked to read and sign a contract that covers areas such as respect and responsibilities during AIME sessions, safety rules about contact with university mentors (no contact outside of AIME) and how they engage at the university campus. This also includes an agreement with the mentees to attend all AIME sessions and to remain in school. They are informed both in writing and by the AIME staff that in order to remain at AIME they need to continue attending school. There is also an expectation of attending at least two-thirds of sessions (but in practice there is a degree of flexibility about this requirement).

Whilst this process could be viewed as an act concerned with compliance and consequences, our observations, together with our discussions with young people, mentors and AIME staff suggest something quite different. The philosophy behind the practice is not one of compulsion, but rather, communicating a belief in the young people's capacity and right to completing their education and exploring further opportunities with employment, training and university. This is exemplified in fieldnotes from all year 9 day 1 sessions. In the example below the presenter introduced the contract in the context of how AIME believes in young Indigenous Australians, a belief underscored by the motto that Indigenous $=$ Success

Welcome talk to year 9 students by the AIME presenter. He connected the 'survival' of the most ancient peoples as based on their capacity to learn and be resourceful, stating "learning is in your blood, always has been. You're here to finish school, study and get a job ...AIME treats you as an adult"... "It all starts now"

The presenter called everyone's attention " $3,2,1$ " and then handed out textbooks explaining the contract. He then read the contract aloud, pointing out the similarities to the AIME rules [which had been explained earlier], he described this to the group as "repetition to emphasise importance". The young people then worked with the university student mentors to complete their contracts (Fieldnotes May 2014, NSW).

This shift in responsibility arguably encourages the mentee to consider finishing school as both a possibility, as something that resides within their power, and significantly, as something that the AIME team and their mentors believe that they can do.

High expectations were also frequently contextualised in cultural histories and practices of respect that are demonstrated by the AIME presenters:

He [the presenter] reminded them [the mentees] that the Elders before them had fought hard for them to be able to attend school and finish year 12 
and he prompted them to think of people they know who did not have this opportunity (Parents, Grandparents, Aunties, Uncles). He then simply stated: "Finish Year 12 as a mark of respect" (Fieldnotes June 2014, NSW, emphasis added).

The quality support offered to mentees to achieve these expectations is provided by AIME staff and mentors in a number of ways. This includes: AIME university based programs, in school Tutor Squads, an online portal connecting year 12 AIME mentees to universities, TAFE (College of Technical and Further Education) and corporate employers; and individualised support for year 12 mentees from AIME staff for transition from school to university, further study and employment. This effort is recognised by the young people, who would often comment on the contributions of the university student mentors and the AIME staff. For example, Tash, a year 12 Mentee explained, "Well, they [AIME staff] put on a lot of programs that really help us and they just give us support basically. To guide us in the right direction." (Tash, year 12 mentee, NSW)

At the micro level, AIME presenters set high expectations for the young people in every AIME program day. These high expectations are evidenced both by the curriculum and the presenters' talk. The curriculum demands high quality output in fast turnaround times. For example, in a single session the young people must: present speeches, create drama performances or write online resume profiles. The presenters' talk explicitly and frequently describes their "high expectations" of participants and recognises the capabilities of each individual (fieldnotes all 2014). This type of discourse serves to explicitly position the young people as assets rather than liabilities that need to be fixed or improved.

Beyond the explicit mentions of high expectations the presenters' talk often calls for, or praises mentees for, "stepping up" or "rising to the [set] challenge" or "stepping outside your comfort zone" (Field notes, all). At AIME, Stepping up is communicated as a means for developing confidence and skills that underpin success both at school and in future careers. For example, in relation to sharing stories, one AIME presenter explained: "The reason we ask you to do all this stepping up is because more and more now you'll be asked to do video entries for job interviews" (Fieldnotes August 2014, ACT). This example could be described as an approach to improving personal confidence and communication skills, and is applicable to both Indigenous and non-Indigenous young people. The subtle difference in the AIME mentoring context is how this approach takes account of barriers to stepping up such as Shame $^{2}$ and it recognises a cultural wealth that connects widely with communities and deeply with the cultural wealth of Ancestors.

\footnotetext{
2 For reasons of space we are unable to fully discuss how AIME works with Shame. This is currently the focus of a manuscript in preparation. Briefly, the AIME program explicitly addresses Shame by having a rule 'No Shame at AIME'. AIME staff and university student mentors each role model this approach and the mentees are consistently invited and encouraged to step up and get involved. The phrase 'No Shame at AIME' is frequently heard throughout AIME sessions. This includes being spoken at the start of the day by the Indigenous AIME staff and we have observed the young people saying it to one another, with the outcome that their peers will then engage in activities.
} 


\section{Recognising aspirations in understandings of what it means to be Indigenous}

In rooms bustling with high school students ranging in ages from thirteen to seventeen, the message Indigenous $=$ Success gets repeated, commented on and discussed by the young people. While Indigenous = Success is a key message of AIME, this is a message that is experienced by mentees as much more than just a corporate slogan. Young people are becoming inspired to think about being Indigenous in terms of success (as opposed to deficit narratives). This understanding is revealed in the interview excerpt with Kyle, a year 9 mentee:

Kyle I know that a few of the mentors that I've met so far are attending University at the moment and that sort of shows that anyone can attend University. Growing up as a kid I always just — sort of stereotyped the people that go to University-you know what I mean? No one from my family's ever been so I just think people [pause]

Interviewer Yeah

Kyle Yeah. It's just a reality check that anyone can go to University Interviewer Okay, so meeting them sort of blew that stereotype a bit out of the water? What did you think-who did you think went to Uni?

Kyle White people, you know successful—people with money-you know what I mean? (Year 9 mentee, NSW, emphasis added)

This is a very powerful account of a young person's reconceptualisation of themself as an Indigenous person who can attend university. Importantly, however, we are not suggesting that Kyle moved from a position of low expectations to one of high expectations. To do so would be to equate high expectations with expecting to go to university. Rather, taking up the idea of cultural wealth (Yosso 2005) we suggest that Kyle had a wealth of expectations of himself and that while some of these didn't align directly with university, by removing the othering effect of racism, the university became a place that could be inclusive of a young Aboriginal person such as himself. To take the opposite view, that Kyle just had low expectations, is to elide the complex and damaging effects that link education and racism.

Kyle's reconceptualisation was not brought about by immersion in posters and websites or through teacher-talk about university. Rather, this is a duo-fold process both brought about by firstly developing relationships with mentors, by visiting and experiencing university campuses as spaces relevant to their lives and secondly, and critically, by being valued for who they are and "what" they bring to the program, the latter involving both the valuing and appreciation of individuals' aspirational capital. Central to this was the message that education and the university was a place where he was welcome, but also where his cultural wealth could be of value to a path in education.

The AIME curriculum further acknowledges the value of the young peoples' cultural identities by providing several opportunities for young people to encounter successful Indigenous Australians. The AIME staff that stand up the front to deliver programs are all young, vibrant and, following this definition of success, successful 
example, the AIME session on Windows to the Future features guest speakers sharing their personal journeys to success. Many of these guests are Indigenous people from a range of professions and backgrounds (for example, university students and graduates, media and sporting personalities, community leaders). In this regard, it is important to emphasise that meanings of success are determined by AIME. This is not a dominant criteria set by Western standards, but in terms of displaying and enacting the values/attributes of Indigenous cultures. During such sessions the AIME presenters are careful to acknowledge the young people as successful for being there, and explain that there are many forms of success (Fieldnotes 2014). In this way the young people are able to directly connect with success at a personal level, and do so in an environment that explicitly recognises them as already enacting this attribute.

\section{Recognising and navigating existing aspiration windows with existing aspiration capitals - meeting the mentees where they are at}

Following Appadurai (2004), we take the concept of narrow aspiration windows and suggest what AIME strives to do is to work with mentees' existing aspiration windows - but not in a way that assumes these are narrow. In this sense, the AIME program is acknowledging and celebrating the mentees' aspirational capital (Yosso 2005). In our view, how AIME does this is to perpetually link the past, present and future in aspirational terms, and in so doing, recognise the navigational capacity that the young people already possess. For instance, in the AIME program there are: firstly learning from the stories of successful people's journey's past; secondly, there is "real help" in the tutor squads that support mentees to reach immediate educational goals such as completing homework and assessments and studying for exams; and thirdly, there is the groundwork for longer term educational and vocational aspirations. Due to space restrictions, we will focus on the latter.

Our interviews with the university student mentors provides insight into AIME's approach to fostering longer term educational and vocational aspirations, and the way that they seek to build confidence.

To to have someone validate that dream and say "Yeah go for it" ... I think it's refreshing for them [the mentees] to hear that (Liam, mentor, Victoria).

It's all positive — no one's putting them down here at AIME. No one's saying "No you can't do that" and at school, it just takes one person to say that and it can just deflate their hopes and their dreams and they go "Oh no, they don't believe in me anymore". They don't believe in themselves. (Cathy, mentor, Victoria)

This approach by the mentors is experienced by mentees in a variety of ways, often around notions of mentors being non-judgemental. For example Steve explained that "they don't judge me":

Steve Well they [the mentors] ask a lot of questions and I like those questions because like-I don't know-it's just [pause] 
Interviewer You like the questions they ask?

Steve Yeah, because then I tell them and then they don't judge me and I like that (Year 9 mentee, NSW)

This idea of being non-judgemental of where mentees are at aligns with AIME's approach of not assuming a 'within mentee' deficit, where aspirations are too narrow and must be improved.

In our interviews and observations the mentees did not report experiencing pressure at AIME to decide on a specific future or study/career trajectory. Some did mention that university was "not for them", and at the same time identified their interests and were buoyed by the encouragement they had experienced. One way this works is through the spaciousness afforded by not focusing on generating or improving aspirations. For example, conversations with mentors about the university experience occur in a way that is easy going. This is quite different to the pressure to decide what to study at university, a pressure that Carly, Jess and Leah, 3 year 10 mentees, align with discussions about university that are held in school contexts:

Carly They [the mentors] sort of take your mind off stuff like stresses and stuff like you come here and like its more chilled laid back conversations and you can talk about Uni without the pressure about Uni sort of thing...

Leah Yeah school makes it so serious and like "Oh you have to decide now" ... whereas you come here and you can talk about what Uni is really like (Carly and Leah, Year 10 mentees, VIC)

The idea of honouring and supporting mentee's existing dreams and aspirations might seem obvious. But in practical terms it manifests in very subtle mentoring practices. To give a sense of this subtly we provide two short vignettes, based on fieldnotes, that demonstrate the generative nature of the AIME mentoring program in terms of working effectively within mentees' aspiration windows.

\section{Vignette 1 -broadening conversations to include university as a possibility}

In the year 12 session where the mentees work with mentors to prepare their profile for the online AIME Yearbook, a mentor is working with a mentee who said she wanted to be a beauty therapist. The mentor asked what sort of therapy she was interested in most and was told that she most enjoyed makeup Initially conversations initiated by the mentor had the effect of narrowing the idea, "If it's make-up you like, you could just focus on make-up artistry? What kind of make-up artistry are you into? Would you like, TV, special effects, weddings?" but the mentee kept the conversation broad, "I don't mind, I just really love working with colours". This statement led to the mentor asking if she enjoyed art, which the mentee said she did. The mentor then began to encourage the mentee to think about all sorts of different professions that work with colour artistically. This sparked the mentee's interest in ideas of graphic design, fashion design, art design for movies. This 
then started discussions about different types of training including attending university (Vignette based on fieldnotes May 2014, NSW).

From beauty therapy to art design for movies, the mentor's initial willingness to engage with and understand the mentee's goal to be a beauty therapist demonstrated the generative nature of working within the mentee's aspiration window. In this example, the mentor's first response was to recognise, work with and hone the mentee's existing goal so as to identify a clear pathway for education and employment options (e.g. make-up for special effects and movies requires different training to salon beauty therapy). However, the mentee did not express certain preference for any of the pathways identified thus far, instead she articulated an overarching skill and interest as driving her career choice, 'working with colours'. The mentor's response then challenged the parameters of the mentee's existing aspiration window. By bringing her personal knowledge of university-based design opportunities to the conversation, the mentor provided the necessary resources to build the mentee's aspirational capital. The mentee's existing aspiration to work artistically with colour was strengthened and developed to include multiple career paths and university as an option for further study. Here, there was no unprompted 'upselling' to university studies, the mentor took her cues from the mentee. Rather, there were simply new conversations regarding new possibilities. Importantly, discussion of university was not always the mentoring outcome. In the second vignette discussion solely focused on the practicalities of realising a dream.

\section{Vignette 2: Meeting young people where they are at}

The presenter had tasked the Year 11 mentees to produce a written list of things they would like to achieve in the next 6 months. The mentee sat there and stared quietly at her page. The mentor asked her what she wanted to be doing in 6 month's time, she replied "dunno". The mentor then started in on some personal goals - "would you like to get your driving license?" The mentee responded positively to some non-school-related goal setting and a few of these were recorded. The mentor said that sometimes we need to work on things now to help set us up for what we want to do later, then she asked her mentee what she wanted to do when she left school. "I want to be a mortician, I want to be an embalmer". After the briefest of pauses, the mentor started to ask questions - "how do you even become a mortician?" The mentee explained that she had found a course in Melbourne. The mentor said that moving interstate can be a bit costly so it might be a good goal to get a casual job in the next 6 months to start saving. The mentor also encouraged her to write down the 6-month goal of contacting the course provider in Melbourne to ask lots of questions: Are there scholarships? How and when do you apply for a 2016 course? (Vignette, based on fieldnotes June 2014, NSW).

In this second mentoring vignette, the mentor recognises the mentee's existing expectations and aspiration to study interstate for her dream job. This vignette did not show a mentor determined to 'expand' the mentee's aspirational window or 
focus on ensuring the mentee's aspirations were somehow improved or raised. Rather, this vignette describes a mentor respectfully working within the mentee's existing aspirational window. Apart from the brief pause that indicated perhaps surprise and/or uncertainty at how to proceed, the mentor did not at any point question becoming a mortician as a career option, nor did the mentor offer alternatives that perhaps better suited her own areas of expertise. There was no unsolicited promotion of university courses in related fields like embalming in biological sciences or ancient history. Instead, the mentor got practical in terms of discussing short-term goals that would support the mentee's long-term goal of becoming a mortician. The mentee knew what she wanted to do, her mentor just helped to "sure up" some ideas and strategies regarding how to start "getting there". In this way the mentee's existing aspirations were strengthened.

In these AIME mentoring vingettes, the mentors centred on the mentees' existing interests and talents. No dream was shut down, and no one pathway promoted as the right one (for example, there was no insistence that university was the best and only pathway to success). The mentors, working with the lead of the AIME presenters, worked with the young people and connected 'where they were at'.

\section{Conclusion}

Yosso's (2005) Community Cultural Wealth framework points to the existing cultural capital of all people; a wealth which AIME recognises and foregrounds. The capacity of the AIME program to acknowledge "a continuity of cultural assets and resources" (Yosso and Garcia 2007, p. 147) within each of the young people both builds engagement with AIME and also, has flow on effects for schooling and education.

Recognising aspiration is a subtle yet powerful driver in the AIME program. Underlying this approach is an assumption that the Indigenous young people bring cultural wealth with them to AIME mentoring sessions, and this is inclusive of aspirations, whatever these may be. In this sense the AIME approach departs from a rigid cultural capital framework that would all too easily cast the young people as deficit. By recognising cultural wealth and the myriad ways the young people have aspirations, AIME is able to connect with the young people, and significantly, connect with a component of the education system that is frequently perceived to be, as Kyle stated, for "White people".

This works, for example, through the AIME curriculum. At face value, the curriculum, a key component of the AIME mentoring program, does not directly teach about goal setting until year 11/12. Instead, the program offers a variety of curriculum based sessions around identity, positive relationships and communication. The question then arises, if AIME is not explicitly teaching about raising aspirations ... How do they impact young Indigenous high school students' educational aspirations so positively?

This paper has sought to think through this complex question by demonstrating three elements of the program that we believe work to this effect. Firstly, AIME works against a neo-liberal emphasis on aspiration that individualises responsbility 
and is deeply embedded in deficit discourses that blame the individual. This neoliberal (and arguably easy) way of conceptualising aspirations not only leaves unacknowledged the structural factors that may impact upon an Indigenous young person's engagement in education, it is also likely to result in a deficit account of a young person and be ignorant of their cultural wealth. For instance, through valorising the dominant cultural capital of the institution of higher education, the cultural wealth of a young person is overlooked. We have outlined how AIME uses a novel mode of program delivery that engages the young people and holds them connected and accountable with a third party for their educational engagement and success. This approach directly connects to the young people and to their cultural connections. Secondly, AIME encourages young people to reconceptualise what it means to be Indigenous by promoting the understanding that "Indigenous $=$ Success". Thirdly, we have demonstrated that AIME engages with aspirations of young people, where their dreams and existing aspirational windows are both validated and honoured.

AIME works with an understanding of Indigenous young people as rich in aspirations, and what the program seeks to develop and fortify is existing aspirational capitals. We note that this approach also helps to build the capacity of those who work (and we might add, research) with Indigenous young people. Thus there are outcomes for participating in AIME that enhance the practices of the diverse range of people who connect with the program. This includes the diversity of university students (who came from a range of backgrounds and degrees) AIME staff, and schoolteachers.

In closing, we suggest that the lessons to be learned from the AIME mentoring program are not only relevant for working with the diversity of Indigenous young people; these approaches to recognising aspiration and respecting culture may well serve to better engage young people both Indigenous and non-Indigenous, by validating their cultural wealth and opening up existing windows of aspiration. 


\section{References}

Australian Institute of Aboriginal and Torres Strait Islander Studies (AIATSIS). (2011). Guidelines for ethical research in australian indigenous studies. Canberra: AIATSIS.

Australian Indigenous Mentoring Experience (AIME). (2014). 2013 Annual Report. Retrieved from http://www.aimementoring.com/about/reports/.

Appadurai, A. (2004). The capacity to aspire: Culture and terms of recognition. In R. Vijayendra \& M. Walton (Eds.), Culture and public action (pp. 59-84). Stanford: Stanford University Press.

Bodkin-Andrews, G., Dillon, A., \& Craven, R. (2010a). Bangawarra'gumada - Strengthening the Spirit: Causal modelling of academic self-concept and patterns of disengagement for Indigenous and NonIndigenous Australian students. Australian Journal of Indigenous Education, 39, 24-39.

Bodkin-Andrews, G. H., Ha, M. T., Craven, R. G., \& Yeung, A. S. (2010b). Construct validation and latent mean differences for the self-concepts of indigenous and non-indigenous students. International Journal of Testing, 10(1), 47-79.

Bodkin-Andrews, G., Harwood, V., McMahon, S., \& Priestly, A. (2013). AIM(E) for completing school and University: Analysing the strength of the Australian indigenous mentoring experience. In R. Craven \& J. Mooney (Eds.), Seeding success in indigenous Australian Higher education: What research says?. New York: Emerald Publishing.

Bourdieu, P. (1986). The forms of capital. In J. Richardson (Ed.), Handbook of theory and research for the sociology of education (pp. 241-257). New York: Greenwood Press.

Bourdieu, P. (1997). The forms of capital. In H. Lauder, P. Brown, \& A. S. Wells (Eds.), Education, culture and economy. London: Oxford University Press.

Bourdieu, P., \& Passeron, J. C. (1977). Reproduction in education, society and culture. London: Sage Publications.

Craven, R., Yeung, A., Munns, G., Bodkin-Andrews, G., Denson, N., \& O'Rourke, V. (2013). Seeding success for Aboriginal Primary School Students. Sydney: University of Western Sydney \& NSW Department of Education and Training.

Dobia, B., Bodkin-Andrews, G., Parada, R., O'Rourke, V., \& Gilbert, S. (2014). Aboriginal Girls Circle: Enhancing connectedness and promoting resilience for Aboriginal girls-Final Pilot Report. Bankstown: University of Western Sydney \& National Association for Prevention of Child Abuse and Neglect.

Dumais, S. A., \& Ward, A. (2009). Cultural capital and first-generation college success. Poetics, 38, 245-265.

Harlow, L. L. (2014). The essence of multivariate thinking: Basic themes and methods: Basic themes and methods. London: Routledge.

Harwood, V., Bodkin-Andrews, G., Clapham, K., O’Shea, S., Wright, J., Kervin, L., \& McMahon, S. (2013). Evaluation of the AIME outreach program. Wollongong: University of Wollongong.

Kenway, J., \& Hickey-Moody, A. (2011). Life chances, lifestyle and everyday aspirational strategies and tactics. Critical Studies in Education, 52(2), 151-163.

KPMG. (2013). Economic evaluation of the australian indigenous mentoring experience program: Final report. Retrieved from http://www.aimementoring.com.

Marsh, H. W., Ellis, L. A., Parada, R. H., Richards, G., \& Heubeck, B. G. (2005). A short version of the self description questionnaire II: Operationalizing criteria for short-form evaluation with new applications of confirmatory factor analyses. Psychological Assessment, 17(1), 81-102.

McDonough, P. M. (1997). Choosing colleges: How social class and schools structure opportunity. Albany: State University of New York Press.

Munns, G., O'Rourke, V., \& Bodkin-Andrews, G. (2013). The 'Seeds Of Success': Schools that work for aboriginal students. Australian Journal of Indigenous Education, 42(1), 1-11.

Raco, M. (2009). From expectations to aspirations: State modernisation, urban policy, and the existential politics of welfare in the UK. Political Geography, 28(7), 436-444.

Sarra, C. (2011). Strong and smart: Towards a pedagogy for emancipation-Education for first peoples. London: Routledge.

Sellar, S., Gale, T., \& Parker, S. (2011). Appreciating aspirations in Australian higher education. Cambridge Journal of Education, 41(1), 37-52.

Walter, M., \& Andersen, C. (2013). Indigenous statistics: A quantitative research methodology. Walnut Creek: Left Coast Press.

Yosso, T. (2005). Whose culture has capital? A critical race theory discussion of community cultural wealth. Race Ethnicity and Education, 8(1), 69-91.

Yosso, T., \& Garcia, D. (2007). "This is no slum!” A critical race theory analysis of community cultural wealth in culture clash's Chavez Ravine. Aztlán: A Journal of Chicano Studies, 32(1), 145-179. 